University of Wollongong

Research Online

Australian Institute for Innovative Materials -

Papers

Australian Institute for Innovative Materials

$1-1-2018$

\title{
Measuring the effective area and charge density of platinum electrodes for bionic devices
}

Alexander R. Harris

University of Wollongong, The HEARing CRC, alexh@uow.edu.au

C Newbold

The HEARing CRC, University of Melbourne

P Carter

Macquarie University

R Cowan

The HEARing CRC, University of Melbourne

Gordon G. Wallace

University of Wollongong, The HEARing CRC, gwallace@uow.edu.au

Follow this and additional works at: https://ro.uow.edu.au/aiimpapers

Part of the Engineering Commons, and the Physical Sciences and Mathematics Commons

Research Online is the open access institutional repository for the University of Wollongong. For further information contact the UOW Library: research-pubs@uow.edu.au 


\title{
Measuring the effective area and charge density of platinum electrodes for bionic devices
}

\author{
Abstract \\ Objective. Neural stimulation is usually performed with fairly large platinum electrodes. Smaller \\ electrodes increase the applied charge density, potentially damaging the electrode. Greater understanding \\ of the charge injection mechanism is required for safe neural stimulation. Approach. The charge injection \\ mechanism and charge injection capacity were measured by cyclic voltammetry. Electrodes were cleaned \\ mechanically or by potential cycling in acidic solutions. The effective electrode area was measured by \\ hydrogen adsorption or reduction of $\mathrm{Ru}(\mathrm{NH} 3) 3+6$. Main results. The water window and safe potential \\ window were affected by changes to electrolyte, electrode size, polishing method and oxygen \\ concentration. Capacitance and Faradaic current contribute to the charge injection capacity. Varying \\ voltammetric scan rate (measurement time), electrode size, polishing method, potential window, \\ electrolyte and oxygen concentration affected the charge injection capacity and ratio of oxidation to \\ reduction charge. Hydrogen adsorption in acidic solutions provided an inaccurate effective electrode \\ area. Reduction of a solution phase redox species with a linear or radial diffusion profile could provide an \\ effective electrode area. The charge density (charge injection capacity divided by electrode area) of a \\ platinum electrode is dependent on the charge injection capacity and electrode area measurement \\ technique. By varying cyclic voltammetric conditions, the charge density of platinum ranged from 0.15 to \\ $5.57 \mathrm{mC} \mathrm{cm}-2$. Significance. The safe potential window, charge injection mechanism, charge injection \\ capacity and charge density of platinum depends on electrolyte, size of the electrode, oxygen \\ concentration and differences in electrode polishing method. The oxidation and reduction charge \\ injection capacities are not equal. Careful control of a platinum electrodes surface may allow larger \\ charge densities and safe use of smaller electrodes. New electrode materials and geometries should be \\ tested in a consistent manner to allow comparison of potential suitability for neural stimulation.

\section{Disciplines} \\ Engineering | Physical Sciences and Mathematics

\section{Publication Details} \\ Harris, A. R., Newbold, C., Carter, P., Cowan, R. \& Wallace, G. G. (2018). Measuring the effective area and \\ charge density of platinum electrodes for bionic devices. Journal of Neural Engineering, 15 (4), \\ 046015-1-046015-12.
}




\title{
Measuring the effective area and charge density of platinum electrodes for bionic devices
}

\author{
Alexander R Harris ${ }^{1,2}{ }^{\oplus}$, Carrie Newbold ${ }^{2,3}$, Paul Carter ${ }^{4}$, Robert Cowan ${ }^{2,3}$ \\ and Gordon G Wallace ${ }^{1,2}$
}

\author{
${ }^{1}$ ARC Centre of Excellence for Electromaterials Science, Intelligent Polymer Research Institute, \\ University of Wollongong, Wollongong, NSW 2522, Australia \\ 2 The HEARing CRC \\ 3 Department of Audiology and Speech Pathology, University of Melbourne, 550 Swanston St, Melbourne \\ 3010, Australia \\ ${ }^{4}$ Cochlear Ltd, Macquarie University, 1 University Ave, NSW 2109, Australia
}

E-mail: alexrharris@gmail.com

Received 21 March 2018

Accepted for publication 29 March 2018

Published

\begin{abstract}
Objective. Neural stimulation is usually performed with fairly large platinum electrodes. Smaller electrodes increase the applied charge density, potentially damaging the electrode. Greater understanding of the charge injection mechanism is required for safe neural stimulation. Approach. The charge injection mechanism and charge injection capacity were measured by cyclic voltammetry. Electrodes were cleaned mechanically or by potential cycling in acidic solutions. The effective electrode area was measured by hydrogen adsorption or reduction of $\mathrm{Ru}\left(\mathrm{NH}_{3}\right)_{6}^{3+}$. Main results. The water window and safe potential window were affected by changes to electrolyte, electrode size, polishing method and oxygen concentration. Capacitance and Faradaic current contribute to the charge injection capacity. Varying voltammetric scan rate (measurement time), electrode size, polishing method, potential window, electrolyte and oxygen concentration affected the charge injection capacity and ratio of oxidation to reduction charge. Hydrogen adsorption in acidic solutions provided an inaccurate effective electrode area. Reduction of a solution phase redox species with a linear or radial diffusion profile could provide an effective electrode area. The charge density (charge injection capacity divided by electrode area) of a platinum electrode is dependent on the charge injection capacity and electrode area measurement technique. By varying cyclic voltammetric conditions, the charge density of platinum ranged from 0.15 to $5.57 \mathrm{mC}$ $\mathrm{cm}^{-2}$. Significance. The safe potential window, charge injection mechanism, charge injection capacity and charge density of platinum depends on electrolyte, size of the electrode, oxygen concentration and differences in electrode polishing method. The oxidation and reduction charge injection capacities are not equal. Careful control of a platinum electrodes surface may allow larger charge densities and safe use of smaller electrodes. New electrode materials and geometries should be tested in a consistent manner to allow comparison of potential suitability for neural stimulation.
\end{abstract}

Keywords: platinum, voltammetry, charge density, electrode area, cochlear implant

\begin{tabular}{|llllll}
\hline JNL:JNE & PIPS: AABA8B & TYPE: PAP & TS: NEWGEN & DATE:9/4/18 & EDITOR: IOP \\
\hline
\end{tabular}




\section{Introduction}

Many diseases are untreatable or refractory to drug treatment. This includes decreasing effectiveness of levodopa for the treatment of Parkinson's disease and limited effectiveness of anticonvulsants for epilepsy sufferers. There has been an increasing trend to use electrical stimulation of tissue to treat various disorders [1]. An electrode implanted into the subthalamic nucleus or the globus pallidus internus can be used to control rigidity, tremor and bradykinesia associated with Parkinson's disease [2]. Deep brain stimulation (DBS) in other regions can be used to treat depression, obsessive compulsive disorder and Tourette syndrome [3]. Electrical stimulation of the spinal cord can alleviate phantom limb pain and other chronic pain. There have been increasing efforts to attach electrodes to the retina to restore vision to the blind [4]. Most well-known is the cochlear implant, where an electrode array is placed into the inner ear to provide auditory cues to the profoundly deaf [5]. Around 400000 cochlear implants have been implanted worldwide since their development in the 1960s.

Electrodes used for bionic applications are typically platinum or platinum-iridium embedded in a non-conductive carrier such as silicone. These electrode materials are highly conductive, hard, stiff and corrosion resistant, ensuring they can survive in the body for long periods. It is currently recommended that children with profound hearing loss as young as 6 months be given a cochlear implant to ensure proper development of their auditory pathway [6]. These patients are expected to use the same cochlear implant for 100 years, requiring excellent biostability and biocompatibility.

Current bionic electrode designs are relatively large compared to the target cells. Charge injected from an electrode will then stimulate a large volume of tissue, potentially leading to undesirable side effects such as frequency spread in cochlear implants and off target stimulation in DBS. The large device footprint can also cause trauma during insertion and lead to a foreign body response with scar tissue encapsulating the electrodes $[7,8]$. In an effort to target more specific regions of tissue and reduce the foreign body response, there is a strong desire therefore to reduce the electrode size. However, as the electrode size is reduced, an equivalent amount of charge passing through the electrode may induce unsafe electrochemical reactions, particularly oxidation and reduction of water. This has led to growing interest in development of novel electrode materials capable of delivering high charge capacities [9-12], unfortunately these materials have had limited success in chronic human applications [13, 14].

Platinum has a complex electrode surface, capable of forming different crystal planes, able to be oxidised and adsorb various species including hydrogen. Charge can be transferred from a platinum electrode into solution or tissue via capacitance and Faradaic reactions [15]. Characterisation of electrochemical mechanisms at platinum electrodes is usually undertaken on single crystals or well defined clean electrode surfaces, as the structure of a platinum surface can have a significant impact on the rate of chemical reactions. As such, numerous publications report novel electrode structures for catalysing different reactions [16, 17]. The properties of these electrodes, including charge capacity, are typically measured in non-biological solutions. In contrast, platinum electrodes used in biological applications have polycrystalline, non-polished surfaces. As a result, the charge injection mechanisms, charge injection capacity (the amount of charge that can be supplied from an electrode within a certain potential window) and charge density (the charge injection capacity divided by the electrode area) of platinum electrodes used in bionic applications are not well understood. Comparison of new electrode materials and geometries to achieve increased charge injection capacities and charge densities can only be fairly reported by using representative platinum surfaces and valid measurement techniques.

This article investigates the potential window, charge injection capacity, charge transfer process, effective electrode area and charge density of platinum electrodes for bionic applications. The impact of solution composition, oxygen concentration, electrode size, electrode polishing method, potential window and measurement time are discussed.

\section{Experimental}

Hexaammineruthenium(III) chloride $\left(\mathrm{Ru}\left(\mathrm{NH}_{3}\right)_{6} \mathrm{Cl}_{3}\right)$, phosphate buffered saline (PBS: $154 \mathrm{mM} \mathrm{NaCl}, 10 \mathrm{mM}$ phosphate buffer, $\mathrm{pH}$ 7.4), sodium chloride, potassium chloride, sodium bicarbonate, calcium chloride, D-glucose (SigmaAldrich), magnesium chloride hexahydrate (Scharlau), monosodium phosphate (Biochemicals) and 98\% sulfuric acid (RCI Labscan), were used as received. An artificial perilymph contained $125 \mathrm{mM} \mathrm{NaCl}, 3.5 \mathrm{mM} \mathrm{KCl}, 25 \mathrm{mM} \mathrm{NaHCO}$, $1.2 \mathrm{mM} \mathrm{MgCl}_{2}, 1.3 \mathrm{mM} \mathrm{CaCl}_{2}, 0.75 \mathrm{mM} \mathrm{NaH}_{2} \mathrm{PO}_{4}$ and $5 \mathrm{mM}$ glucose [18]. Electrodes were $2 \mathrm{~mm}, 0.6 \mathrm{~mm}$ or $25 \mu \mathrm{m}$ diameter platinum discs (CH Instruments) or a cochlear implant with 22 half band, $0.3 \mathrm{~mm}^{2}$ nominal area platinum electrodes (donated by Cochlear Ltd). One electrode of each type was tested. Disc electrodes were polished with $0.3 \mu \mathrm{m}$ alumina slurry on Microcloth polishing cloth (Buehler), rinsed in deionised water and gently dried (Kimwipe) before use; the cochlear implant has not been used for in vivo studies and was not mechanically polished before use. Electrodes were tested in a 3 electrode configuration on a CHI660E potentiostat $(\mathrm{CH}$ Instruments) using a $\mathrm{Ag} / \mathrm{AgCl}(3 \mathrm{M} \mathrm{KCl})$ as reference electrode and $\mathrm{Pt}$ wire as counter electrode. The electrodes were connected to the potentiostat via alligator clips and placed into a beaker of solution. Unless indicated, test solutions were degassed with nitrogen for at least $10 \mathrm{~min}$.

\section{Results}

Mechanically polished electrodes typically produce voltammograms in degassed $0.1 \mathrm{M} \mathrm{NaCl}$ as shown in figure 1 (a). A potential window of 0.8 to $-0.8 \mathrm{~V}$ was used. There is a broad reduction starting at $\sim 50 \mathrm{mV}$ which is associated with platinum oxide reduction. Further reduction current begins at $\sim-500 \mathrm{mV}$ due to hydrogen adsorption. On switching the scan direction, an oxidation current extends to $\sim-390 \mathrm{mV}$ 
a

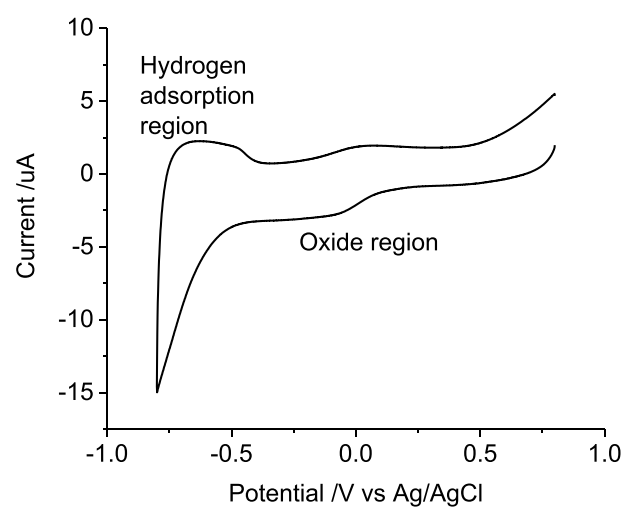

b

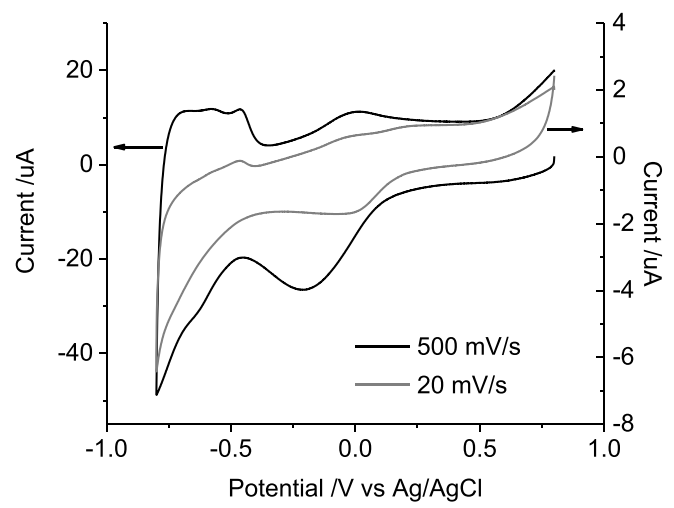

Figure 1. First cycle of a cyclic voltammogram in $0.1 \mathrm{M} \mathrm{NaCl}$ of a mechanically polished $2 \mathrm{~mm}$ diameter platinum electrode (a) at $100 \mathrm{mV}$ $\mathrm{s}^{-1}$ (b) 20 and $500 \mathrm{mV} \mathrm{s}^{-1}$.

Table 1. Charge injection capacity of platinum electrodes from different measurement techniques.

\begin{tabular}{|c|c|c|c|c|c|c|}
\hline \multirow[b]{2}{*}{ Electrode diameter } & \multirow[b]{2}{*}{ Polish method } & \multirow[b]{2}{*}{ Solution } & \multirow[b]{2}{*}{$\begin{array}{l}\text { Scan rate } \\
\left(\mathrm{mV} \mathrm{s}^{-1}\right)\end{array}$} & \multirow[b]{2}{*}{$\begin{array}{l}\text { Potential } \\
\text { window (V) }\end{array}$} & \multicolumn{2}{|c|}{ Charge injection capacity $(\mu \mathrm{C})$} \\
\hline & & & & & Reduction sweep & $\begin{array}{l}\text { Oxidation } \\
\text { sweep }\end{array}$ \\
\hline $2 \mathrm{~mm}$ & Mechanical & $0.1 \mathrm{M} \mathrm{NaCl}$ & 100 & 0.8 to -0.8 & 43.5 & 30.9 \\
\hline $2 \mathrm{~mm}$ & Mechanical & $0.1 \mathrm{M} \mathrm{NaCl}$ & 20 & 0.8 to -0.8 & 107.8 & 48.3 \\
\hline $2 \mathrm{~mm}$ & Mechanical & $0.1 \mathrm{M} \mathrm{NaCl}$ & 500 & 0.8 to -0.8 & 39.7 & 30.7 \\
\hline $600 \mu \mathrm{m}$ & Mechanical & $0.1 \mathrm{M} \mathrm{NaCl}$ & 100 & 0.8 to -0.8 & 4.44 & 1.92 \\
\hline $25 \mu \mathrm{m}$ & Mechanical & $0.1 \mathrm{M} \mathrm{NaCl}$ & 100 & 0.8 to -0.8 & $32.0 \times 10^{-3}$ & $4.7 \times 10^{-3}$ \\
\hline $2 \mathrm{~mm}$ & Mechanical & $0.1 \mathrm{M} \mathrm{NaCl}$ & 100 & 0.8 to 0.2 & 4.1 & 8.2 \\
\hline $600 \mu \mathrm{m}$ & Mechanical & PBS & 100 & 0.8 to -0.8 & 5.0 & 3.7 \\
\hline $600 \mu \mathrm{m}$ & Mechanical & Artificial perilymph & 100 & 0.8 to $\theta .8_{1}$ & 6.5 & 3.6 \\
\hline $2 \mathrm{~mm}$ & Mechanical & Artificial perilymph & 100 & 0.8 to -0.8 & 45.3 & 40.3 \\
\hline $2 \mathrm{~mm}$ & Mechanical & PBS & 100 & 0.8 to -0.8 & 72.1 & 51.6 \\
\hline $2 \mathrm{~mm}$ & Mechanical & PBS with oxygen & 100 & 0.8 to -0.8 & 102.6 & 35.9 \\
\hline $2 \mathrm{~mm}$ & Acid & $0.1 \mathrm{M} \mathrm{NaCl}$ & 100 & 0.8 to -0.8 & 129.5 & 76.7 \\
\hline Cochlear implant & - & $0.1 \mathrm{M} \mathrm{NaCl}$ & 100 & 0.8 to -0.8 & 5.9 & 5.8 \\
\hline
\end{tabular}

from hydrogen desorption. A broad oxidation current then begins at $\sim-190 \mathrm{mV}$ due to oxide formation. A larger oxidation current then occurs from $\sim 460 \mathrm{mV}$. The charge passed during the reduction sweep was $43.5 \mu \mathrm{C}$ and the oxidation current from the oxidation sweep was $30.9 \mu \mathrm{C}$. $1.7 \mu \mathrm{C}$ of reduction charge was passed during the oxidation sweep. A summary of all the charge injection capacity measurements is listed in table 1.

Varying the scan rate to $20 \mathrm{mV} \mathrm{s}^{-1}$ or $500 \mathrm{mV} \mathrm{s}^{-1}$ altered the background current, and the Faradaic peaks became more pronounced with higher scan rates (figure 1(b)). The charge passed during the reduction sweep decreased from $107.8 \mu \mathrm{C}$ at $20 \mathrm{mV} \mathrm{s}^{-1}$ to $39.7 \mu \mathrm{C}$ at $500 \mathrm{mV} \mathrm{s}^{-1}$ and the oxidation charge from the oxidation sweep changed from $48.3 \mu \mathrm{C}$ at $20 \mathrm{mV} \mathrm{s}^{-1}$ to $30.7 \mu \mathrm{C}$ at $500 \mathrm{mV} \mathrm{s}^{-1}$. The amount of reduction charge passed during the oxidation sweep also decreased from $17.5 \mu \mathrm{C}$ at $20 \mathrm{mV} \mathrm{s}^{-1}$ to $1.0 \mu \mathrm{C}$ at $500 \mathrm{mV} \mathrm{s}^{-1}$.

The effect of electrode size on mechanically polished platinum was assessed (figure 2). As expected, smaller electrode areas decrease the current magnitude. The $600 \mu \mathrm{m}$ diameter electrode displayed a reduction peak at $-70 \mathrm{mV}$ while the potentials associated with the other processes were very similar to the $2 \mathrm{~mm}$ diameter electrode. The $25 \mu \mathrm{m}$ diameter microelectrode reduction current began around $50 \mathrm{mV}$, with the reduction sweep crossing the oxidation sweep at $\sim-30$ and $-150 \mathrm{mV}$. The hydrogen adsorption and desorption occurred at the same potentials as the larger electrodes, although the oxide formation was less pronounced. On the $600 \mu \mathrm{m}$ diameter electrode the charge from the reduction sweep was $4.44 \mu \mathrm{C}$, the oxidation charge was $1.92 \mu \mathrm{C}$ and the amount of reduction charge on the oxidation sweep was $0.14 \mu \mathrm{C}$. On the reductive sweep, the $25 \mu \mathrm{m}$ diameter microelectrode passed a reductive charge below $592 \mathrm{mV}$. The total reductive charge from the reductive sweep was $32.0 \mathrm{nC}$. The total reductive charge passed over the whole voltammogram was $58.8 \mathrm{nC}$. On the oxidative sweep, an oxidation current was passed above $79 \mathrm{mV}$ and the total oxidation charge was only $4.7 \mathrm{nC}$.

The potential limits chosen for figures 1 and 2 were defined by the increases in Faradaic current seen at 0.8 and $-0.8 \mathrm{~V}$. However there are clearly other Faradaic reactions present within this potential window (ie. reduction processes at 50 and $-500 \mathrm{mV}$ and oxidation processes at $-390,-190$ and $460 \mathrm{mV}$ ). The specific choice of potential window will affect 


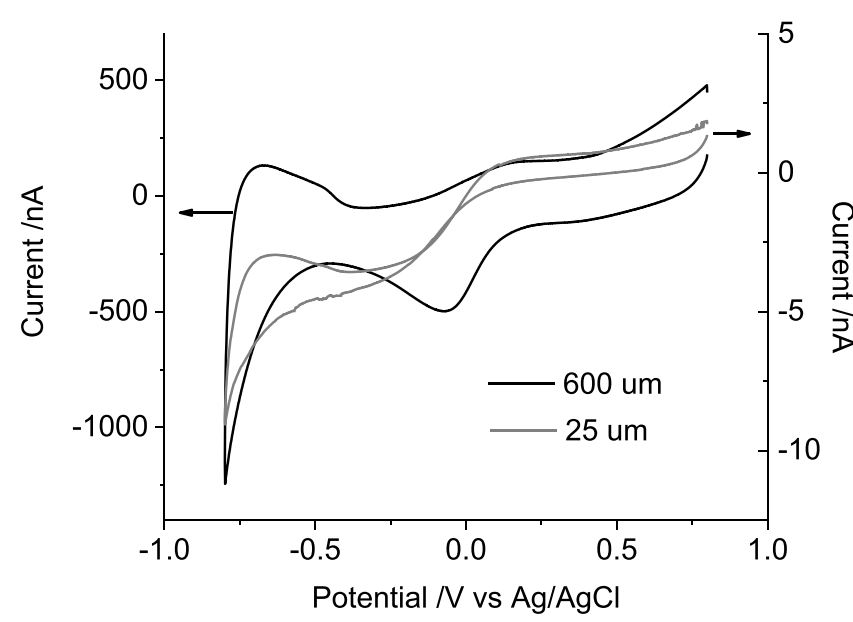

Figure 2. First cycle of a cyclic voltammogram in $0.1 \mathrm{M} \mathrm{NaCl}$ at $100 \mathrm{mV} \mathrm{s}^{-1}$ of mechanically polished platinum electrodes with $0.6 \mathrm{~mm}$ or $25 \mu \mathrm{m}$ diameter.

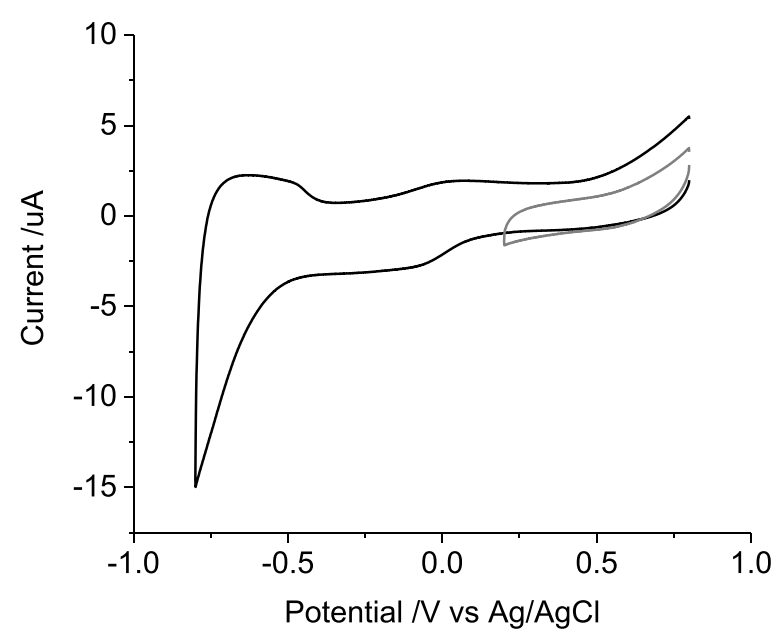

Figure 3. First cycle of a cyclic voltammogram in $0.1 \mathrm{M} \mathrm{NaCl}$ of a mechanically polished $2 \mathrm{~mm}$ diameter platinum electrode at 100 $\mathrm{mV} \mathrm{s}^{-1}$ over different potential windows (black -0.8 to $-0.8 \mathrm{~V}$, grey -0.8 to $-0.2 \mathrm{~V}$ ).

the total charge measured for the oxidation and reduction sweeps. For example, limiting the potential window between 0.8 and $0.2 \mathrm{~V}$ (figure 3) removes the Faradaic current associated with hydrogen adsorption. On a $2 \mathrm{~mm}$ diameter electrode, the reduction charge from the reduction sweep was $4.1 \mu \mathrm{C}$ and the oxidation charge from the oxidation sweep was $8.2 \mu \mathrm{C}$.

Changes to the electrolyte can affect the capacitance at the electrode surface. In the Helmholtz model, the charge density $(\sigma)$ has the following relationship;

$$
\sigma=\frac{\varepsilon \varepsilon_{0}}{d} V
$$

where $\varepsilon$ is the dielectric constant, $\varepsilon_{0}$ is the permittivity of free space, $d$ is the double layer thickness and $V$ is the voltage drop across the double layer. Changes to the electrolyte concentration and composition can affect the dielectric constant and double layer thickness. The electrolyte may also undergo Faradaic reactions (e.g. oxidation of $\mathrm{Cl}^{-}$to $\mathrm{Cl}_{2}$ ) or adsorb onto the electrode surface, either generating or blocking other Faradaic reactions. Voltammetry of mechanically polished

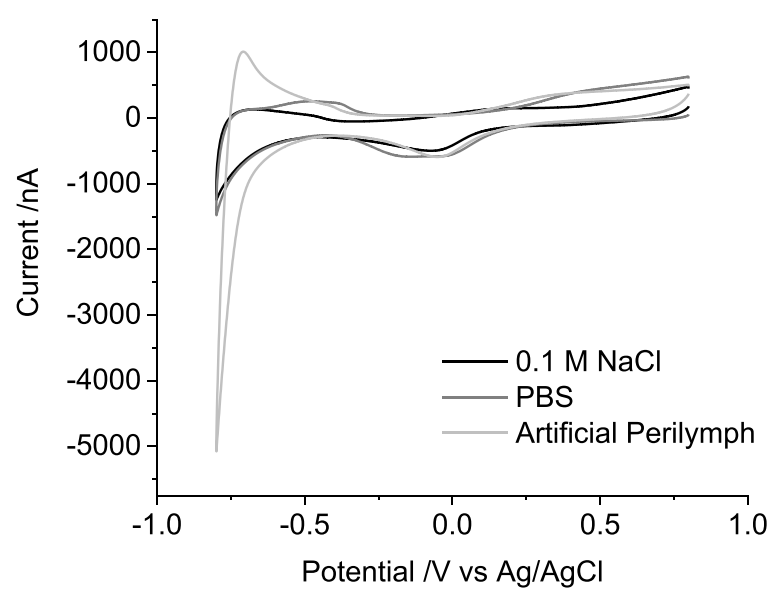

Figure 4. First cycle of a cyclic voltammogram at $100 \mathrm{mV} \mathrm{s}^{-1}$ with a mechanically polished $0.6 \mathrm{~mm}$ diameter platinum electrode in 0.1 $\mathrm{M} \mathrm{NaCl}, \mathrm{PBS}$ or artificial perilymph.

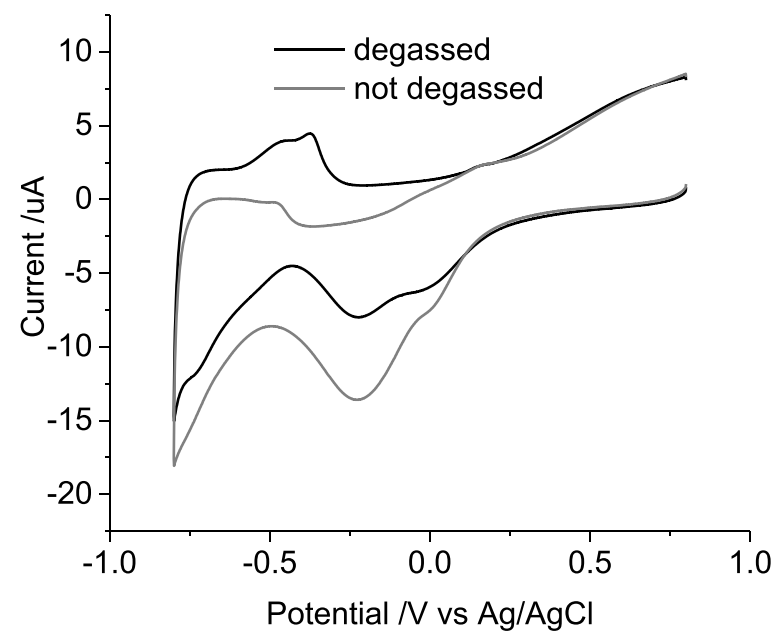

Figure 5. First cycle of a cyclic voltammogram at $100 \mathrm{mV} \mathrm{s}^{-1}$ with a mechanically polished $2 \mathrm{~mm}$ diameter platinum electrode in PBS before and after degassing with nitrogen.

platinum in PBS displayed a broader reduction current from $\sim 270 \mathrm{mV}$ to $-430 \mathrm{mV}$ compared to $0.1 \mathrm{M} \mathrm{NaCl}$ (figure 4). The hydrogen adsorption current was very similar between PBS and $0.1 \mathrm{M} \mathrm{NaCl}$. The hydrogen desorption was significantly larger and shifted to more positive potentials in PBS, extending from $\sim-630 \mathrm{mV}$ to $-280 \mathrm{mV}$. The oxidation current was also larger and positively shifted in PBS compared to $0.1 \mathrm{M} \mathrm{NaCl}$, which may be due to phosphate adsorption and its affect on oxide formation $[19,20]$. At a $600 \mu \mathrm{m}$ diameter electrode in PBS, the reduction charge from the reduction sweep was 5.0 $\mu \mathrm{C}$ and the oxidation charge from the oxidation sweep was $3.7 \mu \mathrm{C}$. In an artificial perilymph, the reduction current extended from $\sim 200 \mathrm{mV}$ to $-300 \mathrm{mV}$, hydrogen reduction began at more positive potentials, $\sim-530 \mathrm{mV}$. A small shoulder appeared on the hydrogen desorption at -420 $\mathrm{mV}$ and oxide formation began around $140 \mathrm{mV}$. The reduction charge on the reduction sweep was $6.5 \mu \mathrm{C}$ and the oxidation charge on the oxidation sweep was $3.6 \mu \mathrm{C}$.

Oxygen is a redox active species that can be irreversibly reduced at an electrode surface. A platinum electrode in PBS that has not been degassed with nitrogen had a larger 
a

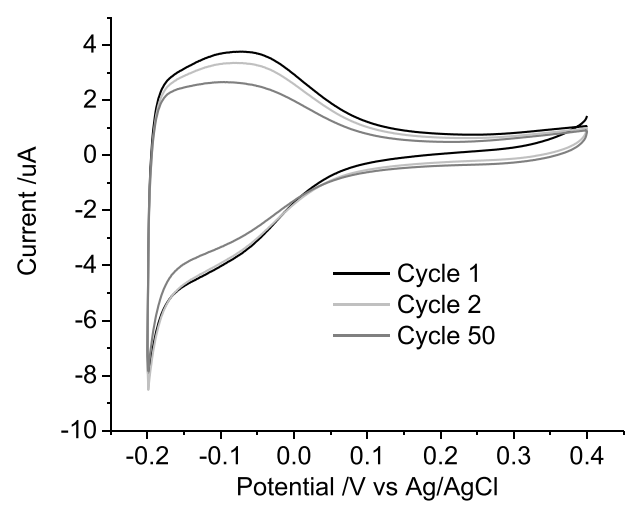

b

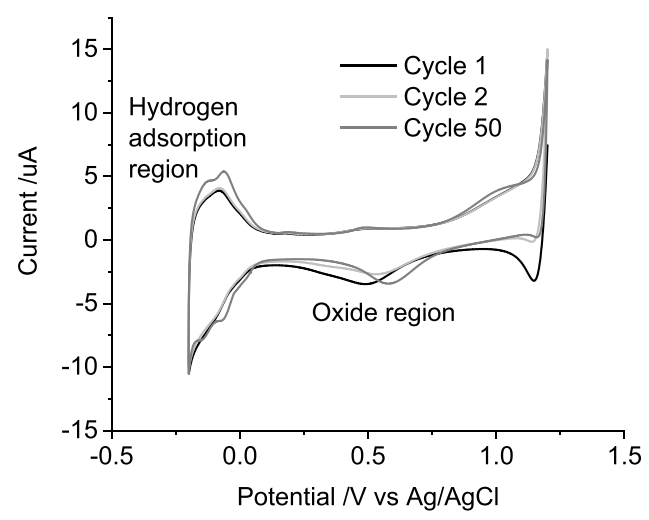

C

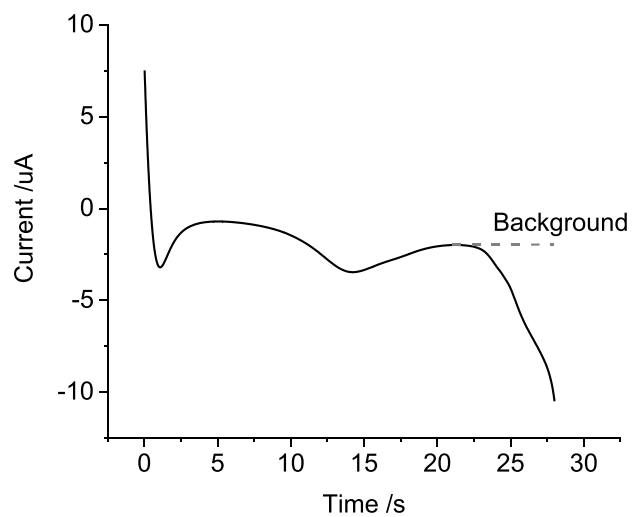

Figure 6. First, second and fiftieth cycle of a mechanically polished $2 \mathrm{~mm}$ diameter platinum electrode in $0.5 \mathrm{M} \mathrm{H}_{2} \mathrm{SO}_{4}$ at $50 \mathrm{mV} \mathrm{s}$. (a) The hydride adsorption region, (b) the oxygen and hydride adsorption regions. (c) Current-time plot of a voltammogram with background subtraction line (dash) used for determining hydride adsorption charge.

reduction current with a peak at $-228 \mathrm{mV}$ (figure 5). It also decreased the hydrogen desorption current significantly. On a $2 \mathrm{~mm}$ diameter electrode in PBS, the reduction charge from the reduction sweep increased from $72.1 \mu \mathrm{C}$ to $102.6 \mu \mathrm{C}$ and the oxidation charge from the oxidation sweep decreased from $51.6 \mu \mathrm{C}$ to $35.9 \mu \mathrm{C}$ after degassing and without degassing respectively.

Mechanically polishing a platinum electrode is able to remove some physically adsorbed contaminants, but can leave other contaminants, oxide functionality and a rough surface with crystal defects. Removal of platinum oxide and crystal defects can be achieved by placing the electrode into a flame. However the high temperatures are incompatible with the protective sheath around the commercially available electrodes and the silicone sheath on a cochlear implant. The electrode surface can also be cleaned by cycling the potential in a 0.5 $\mathrm{M} \mathrm{H}_{2} \mathrm{SO}_{4}$ solution. A mechanically polished electrode placed into $0.5 \mathrm{M} \mathrm{H}_{2} \mathrm{SO}_{4}$ displayed a broad reduction and oxidation process below $0 \mathrm{~V}$. No changes occurred after 50 potential cycles over the hydrogen adsorption region $(0.4$ to $-0.2 \mathrm{~V})$ (figure 6(a)). Extending the positive potential limit to $1.2 \mathrm{~V}$ includes the oxide formation and removal process (figure 6(b)). On the first cycle the oxide reduction peak appears at $490 \mathrm{mV}$, the hydrogen adsorption process is featureless from $50 \mathrm{mV}$, the hydrogen desorption forms a peak at $-83 \mathrm{mV}$ and oxide formation begins at $\sim 800 \mathrm{mV}$. By the 50th cycle, the oxide reduction peak decreased in magnitude and shifted to $580 \mathrm{mV}$. Three processes have become visible in the hydrogen adsorption region, a shoulder at $\sim 20 \mathrm{mV}$, and small peaks at $-73 \mathrm{mV}$ and $-153 \mathrm{mV}$. The hydrogen desorption region also displays three processes, shoulders at $\sim-120 \mathrm{mV}$ and $\sim 30 \mathrm{mV}$ and a peak at $-60 \mathrm{mV}$. The small peak splitting $(\sim 10-30 \mathrm{mV})$ between the oxidation and reduction peaks is typical of surface confined processes. The broad oxide formation process occurs at similar potentials and has increased slightly in magnitude.

The charge associated with the hydrogen adsorption has been used to determine the effective electrode area [21]. The voltammogram in figure $6(\mathrm{~b})$ is converted to a time versus current plot and a baseline subtraction performed over the capacitance region ( 100-200 mV) (figure 6(c)). Integration of the reduction sweep from $\sim 50$ to $-200 \mathrm{mV}$ provides the charge associated with hydrogen adsorption. On the first cycle, the charge was $17.7 \mu \mathrm{C}$, this increased to $22.1 \mu \mathrm{C}$ after 50 cycles.

If an acid polished $2 \mathrm{~mm}$ diameter platinum electrode is placed into $0.1 \mathrm{M} \mathrm{NaCl}$, the voltammetry is significantly different to a mechanically polished electrode (figure 7). A reduction process begins around $370 \mathrm{mV}$, a small, sharp peak appears at $28 \mathrm{mV}$, a shoulder forms at $\sim-260 \mathrm{mV}$ and a large reduction peak appears at $-386 \mathrm{mV}$. On the oxidation sweep, 
a large peak occurs at $-317 \mathrm{mV}$ with small processes present at $-215 \mathrm{mV},-145 \mathrm{mV}$ and $182 \mathrm{mV}$. The reduction charge from the reduction sweep was $129.5 \mu \mathrm{C}$, the oxidation charge from the oxidation sweep was $76.7 \mu \mathrm{C}$ and the reduction charge on the oxidation sweep was $36.2 \mu \mathrm{C}$. Mechanically polishing the electrode largely returns the electrode to its original state, although the oxide removal process has shifted to more positive potentials and a small oxidation peak remains at $-194 \mathrm{mV}$. The reduction charge on the reduction sweep was $54.9 \mu \mathrm{C}$, the oxidation charge on the oxidation sweep was $19.8 \mu \mathrm{C}$ and the reduction charge on the oxidation sweep was $3.0 \mu \mathrm{C}$.

The effective electrode area can also be determined by the reduction of a solution phase redox species such as $\mathrm{Ru}\left(\mathrm{NH}_{3}\right)_{6}^{3+}$. At fast voltammetric scan rates, diffusion of $\mathrm{Ru}\left(\mathrm{NH}_{3}\right)_{6}^{3+}$ to the electrode surface is linear, and if the response is reversible, the electrode area can be determined by measuring the current of the one electron reduction process

$$
\mathrm{Ru}\left(\mathrm{NH}_{3}\right)_{6}^{3+}+e^{-} \rightleftharpoons \mathrm{Ru}\left(\mathrm{NH}_{3}\right)_{6}^{3+}
$$

where the peak current $\left(i_{\mathrm{p}}\right)$ is related to electrode area $(A)$ by

$$
i_{\mathrm{p}}=\left(2.69 \times 10^{5}\right) n^{3 / 2} A D^{1 / 2} C v^{1 / 2}
$$

with $n$ the number of electrons transferred, $D$ is the diffusion coefficient $\left(9.0 \times 10^{-6} \mathrm{~cm}^{2} \mathrm{~s}^{-1}\right), C$ is the concentration and $\nu$ is the voltammetric scan rate [22]. At slow voltammetric scan rates, a radial diffusion profile occurs, so that the area of a disc electrode is related to a steady-state current $\left(i_{\mathrm{ss}}\right)$

$$
i_{\mathrm{ss}}=4 n F D C r
$$

where $F$ is the Faraday constant and $r$ is the electrode radius [22]. On a $2 \mathrm{~mm}$ diameter platinum electrode, voltammetry of $5 \mathrm{mM} \mathrm{Ru}\left(\mathrm{NH}_{3}\right)_{6}^{3+}$ at $100 \mathrm{mV} \mathrm{s}^{-1}$ produced a response typical of linear diffusion with a reduction peak at $-107 \mathrm{mV}$ and an oxidation peak at $-30 \mathrm{mV}$, giving a peak splitting of $77 \mathrm{mV}$ (figure 8(a)). The reduction peak current was $35.3 \mu \mathrm{A}$ and the oxidation peak current was $32.4 \mu \mathrm{A}$. This gives an average effective area of $2.65 \times 10^{-2} \mathrm{~cm}^{2}$. On a $25 \mu \mathrm{m}$ diameter microelectrode, a scan rate of $3 \mathrm{~V} \mathrm{~s}^{-1}$ produced reduction and oxidation peaks at $-109 \mathrm{mV}$ and $-25 \mathrm{mV}$ (peak splitting of 84 $\mathrm{mV}$ ) with magnitudes of $43.6 \mathrm{nA}$ and $36.6 \mathrm{nA}$. This produces an average linear diffusion effective area of $5.74 \times 10^{-6} \mathrm{~cm}^{2}$. At a scan rate of $10 \mathrm{mV} \mathrm{s}^{-1}$, a steady-state sigmoidal response is observed with a limiting current of $18.34 \mathrm{nA}$ equating to a radial diffusion electroactive area of $3.5 \times 10^{-6} \mathrm{~cm}^{2}$ giving a roughness factor of 1.64 (figure 8(b)).

A cochlear implant is composed of platinum bands embedded in a silicone carrier. The implants are largely handmade, resulting in relatively large variance in electrode area. The silicone may also block some of the platinum surface, reducing the effective area. The curved geometry of the platinum and the flexible, delicate structure of the array make mechanical polishing difficult. Cleaning in a flame is also not possible, leaving potential cycling in acidic solutions. While cochlear implants are cleaned by various washing steps, they are not mechanically polished or cleaned by potential cycling in acidic solutions prior to implantation, so measurement of

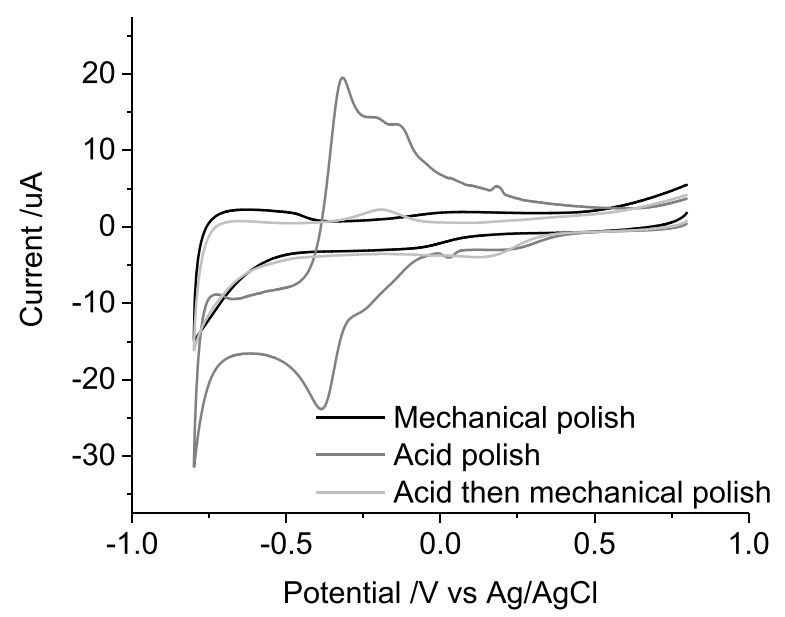

Figure 7. First cycle of a cyclic voltammogram at $100 \mathrm{mV}$ $\mathrm{s}^{-1}$ in $0.1 \mathrm{M} \mathrm{NaCl}$ of a $2 \mathrm{~mm}$ diameter platinum electrode after mechanically polishing, acid polishing (50 cycles of cleaning in $0.5 \mathrm{M} \mathrm{H}_{2} \mathrm{SO}_{4}$ at $50 \mathrm{mV} \mathrm{s}^{-1}$ from 1.2 to $-0.2 \mathrm{~V}$ ) and acid polishing followed by mechanical polishing.

the charge injection capacity and effective electrode area after these polishing steps is not representative of the electrodes' performance in vivo. The voltammetry of a cochlear implant in degassed $0.1 \mathrm{M} \mathrm{NaCl}$ is shown in figure 9(a). A small shoulder on the reduction sweep begins around $0 \mathrm{~V}$ with a larger reduction current at $-210 \mathrm{mV}$. The forward and reverse sweeps cross-over at $-219 \mathrm{mV}$ and $-620 \mathrm{mV}$. The charge passed on the reduction sweep was $5.9 \mu \mathrm{C}$, the reduction charge passed on the oxidation sweep was $5.8 \mu \mathrm{C}$ and only 1.1 $\mu \mathrm{C}$ of oxidation charge was passed on the oxidation sweep. The effective electrode area was measured by the addition of $5 \mathrm{mM} \mathrm{Ru}\left(\mathrm{NH}_{3}\right)_{6}^{3+}$. The electrode displayed voltammetry of predominantly linear diffusion at all useful scan rates. At 50 $\mathrm{mV} \mathrm{s}^{-1}$, reduction and oxidation peaks were found at -126 $\mathrm{mV}$ and $-53 \mathrm{mV}$ ( $73 \mathrm{mV}$ peak splitting) with magnitudes of $2.64 \mu \mathrm{A}$ and $1.81 \mu \mathrm{A}$ respectively (figure $9(\mathrm{~b})$ ). This equates to an average effective electrode area of $2.47 \times 10^{-3} \mathrm{~cm}^{2}$, slightly smaller than the nominal area.

\section{Discussion}

\subsection{Potential window}

Cyclic voltammetry is a simple and fast technique for measuring the capacitance and Faradaic components at an electrode-solution interface [23]. It is routinely used for measuring the charge injection capacity of electrodes for bionic applications. Typically, the potential is swept from a positive to a negative potential. The range from maximum to minimum potential is termed the potential window and the safe potential window is defined as the voltage range over which the electrode, electrolyte and solvent are neither oxidised nor reduced. In biological systems, this potential range is largely determined by the oxidation and reduction of water (water window). The safe potential window is not an exact value; the rate of reaction increases with overpotential. At small overpotentials, the charge associated with water oxidation and reduction is small, 
a

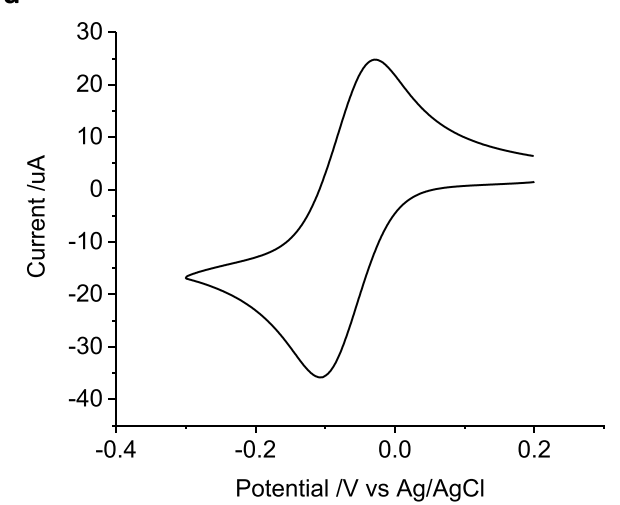

b

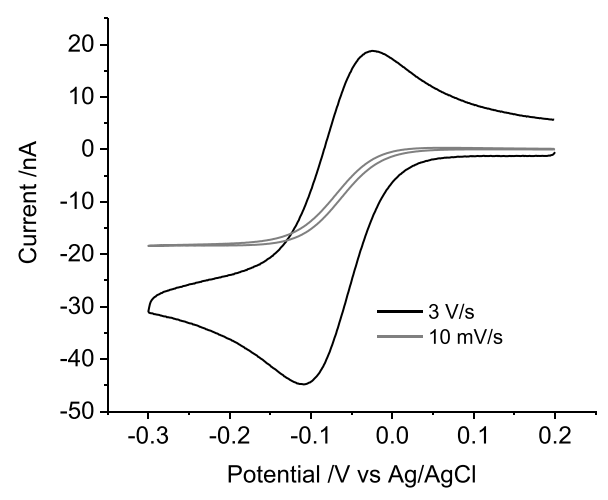

Figure 8. Cyclic voltammetry of $5 \mathrm{mM} \mathrm{Ru}\left(\mathrm{NH}_{3}\right)_{6}^{3+}$ in $0.1 \mathrm{M} \mathrm{NaCl}$ (a) mechanically polished $2 \mathrm{~mm}$ diameter platinum electrode at $100 \mathrm{mV}$ $\mathrm{s}^{-1}$ (b) mechanically polished $25 \mu \mathrm{m}$ diameter platinum electrode at $10 \mathrm{mV} \mathrm{s}^{-1}$ or $3 \mathrm{~V} \mathrm{~s}^{-1}$.

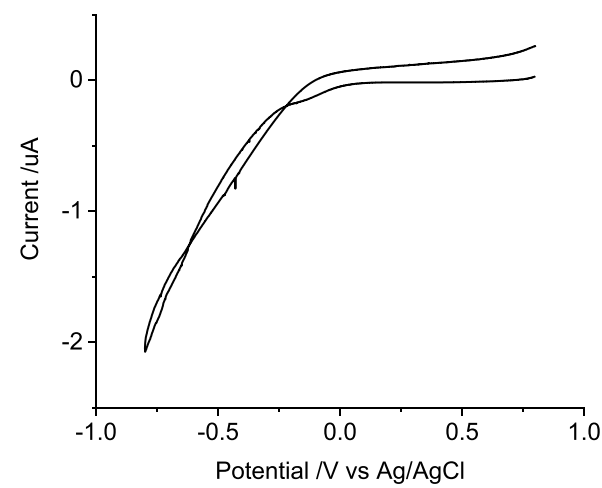

b

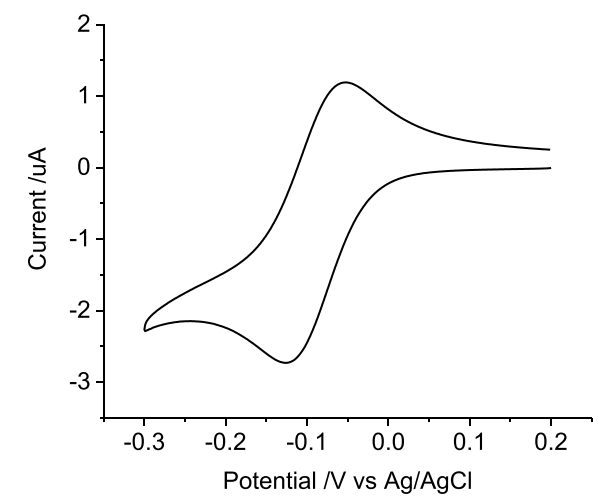

Figure 9. Cyclic voltammetry of a non-polished cochlear implant platinum electrode $\left(0.3 \mathrm{~mm}^{2}\right.$ nominal area) in (a) $0.1 \mathrm{M} \mathrm{NaCl}$ at $100 \mathrm{mV}$ $\mathrm{s}^{-1}$ and (b) $5 \mathrm{mM} \mathrm{Ru}\left(\mathrm{NH}_{3}\right)_{6}^{3+}$ at $50 \mathrm{mV} \mathrm{s}^{-1}$.

and barely noticeable on a cyclic voltammogram. However, chronic stimulation at these potentials may still lead to significant generation of reactive species, which may degrade the electrode or damage nearby tissue. This has led to a conservative estimate of the safe potential window [24].

Various factors can influence the safe potential window. The water window can be affected by the electrode surface. Different platinum structures are catalytic to water breakdown, reducing the required overpotential [25]. Other electrode materials, such as boron doped diamond require larger overpotentials, significantly increasing the water window [26]. The electrode and components in solution can also undergo undesired Faradaic reactions. If this occurs within the water window, the safe potential window is further diminished. Therefore, the most accurate measure of an electrode's safe potential window must be obtained in a biologically relevant solution, not simple electrolytes such as $0.5 \mathrm{M} \mathrm{H}_{2} \mathrm{SO}_{4}$. PBS is one common solution used for biological research, but is still not a true representation of biological tissue, as it does not contain any organic components and the buffering chemicals are different. An artificial perilymph has been used regularly for modelling cochlear implant performance, but it still lacks most organic species [18]. Solution composition also varies with location, while cochlear implant electrodes are mainly exposed to perilymph, there is a different chemical matrix in other fluids within the inner ear, cerebral spinal fluid, and tissue around electrodes placed into the brain or on peripheral nerves $[27,28]$. The time after implantation and degree of tissue encapsulation may also affect the potential window as various proteins may adsorb onto the electrode surface and different cells and fibres may form around the implant. As a result, great care must be taken when defining the potential window of an electrode for bionic applications. The most accurate measure of the safe potential window will be obtained over the lifetime of the electrode in vivo.

The effect of electrolyte on the water window has been discussed previously and was very similar between $0.13 \mathrm{M} \mathrm{NaCl}$ and PBS but shifted to more positive potentials in $\mathrm{H}_{2} \mathrm{SO}_{4}$ $[29,30]$. In this work, the maximum applied potential was $0.8 \mathrm{~V}$, which is within the water window. The water window was similar between $0.1 \mathrm{M} \mathrm{NaCl}$ and PBS, seen to shift to more positive potentials in artificial perilymph (figure 4), and slightly reduced in $0.5 \mathrm{M} \mathrm{H}_{2} \mathrm{SO}_{4}$ (figure $6(\mathrm{~b})$ ). The size of the electrode, oxygen concentration or difference in polishing method did not greatly affect the water window. However variation in these properties did result in larger Faradaic current which may reduce the safe potential window. 


\subsection{Charge injection mechanism and charge injection capacity}

The charge injection capacity can be calculated from a cyclic voltammogram by transforming the current-potential plot to a current-time plot and integrating over specific regions. Typically only the charge passed on the reduction sweep is reported. At an ideally polarisable electrode, the charge passed during a cyclic voltammogram would be completely attributed to capacitance. The charge passed on oxidation and reduction sweeps would be equivalent, and reporting of only one sweep direction would be sufficient for characterising an electrode. In practice, no electrode, especially in the complex tissue environment, achieves this ideal behaviour. The presence of a Faradaic reaction affects charge transfer across the double layer. A fully reversible Faradaic reaction may provide equivalent oxidation and reduction charge; however any irreversibility or loss of product by reaction or diffusion away from the electrode surface would reduce this equivalency. The voltammetry of a platinum electrode displays a number of Faradaic reactions with different reaction rates that significantly impact the charge equivalency. This can result in different safe charge injection capacities for reduction and oxidation charge. Recent current pulsing experiments of platinum electrodes in $\mathrm{H}_{2} \mathrm{SO}_{4}$ and subcutaneous tissue also suggest different charge injection capacities for reduction and oxidation pulses, with application of high charge resulting in platinum dissolution $[31,32]$.

The charge injection capacity of platinum over the water window includes both the oxide and hydrogen adsorption regions (figure 1(a)). At a scan rate of $100 \mathrm{mV} \mathrm{s}^{-1}$ the charge passed during the reduction sweep was $43.5 \mu \mathrm{C}$ and the oxidation charge from the oxidation sweep was $30.9 \mu \mathrm{C}$, giving 1.4 times more reduction than oxidation charge injection capacity. Decreasing the scan rate increases the diffusion layer thickness and the charge injection capacity. For reactions with different rates, variations in scan rate (measurement times) can also impact on the charge injection capacity. These effects of measurement time may have different impacts on the oxidation and reduction charge. Lowering the scan rate to $20 \mathrm{mV}$ $\mathrm{s}^{-1}$ increased the reduction charge injection capacity to 2.2 times greater than the oxidation charge injection capacity (figure 1(b)). This impact of measurement time means characterisation of electrodes must be performed at multiple voltammetric scan rates.

The electrode area will affect the charge injection capacity and has been demonstrated previously with iridium oxide electrodes [33]. The capacitance $\left(C_{\mathrm{d}}\right)$ is proportional to the electrode area

$$
C_{\mathrm{d}}=\varepsilon \varepsilon_{0} A / d
$$

while mass transport governs the relationship between electrode area and Faradaic current (i.e. compare equations (2) and (3)). At a scan rate of $100 \mathrm{mV} \mathrm{s}^{-1}$, decreasing the electrode diameter to $600 \mu \mathrm{m}$ lowered the reduction charge to $4.44 \mu \mathrm{C}$ and the oxidation charge to $1.92 \mu \mathrm{C}$; increasing the reduction charge injection capacity to 2.3 times greater than the oxidation charge injection capacity (figure 2). At a $25 \mu \mathrm{m}$ diameter microelectrode, a reduction charge of $32.0 \mathrm{nC}$ and oxidation charge of $4.7 \mathrm{nC}$ resulted in 6.8 times greater reduction charge injection capacity. These changes in charge and charge equivalency with electrode area can be fit with a quadratic equation. A diffusion layer is created in the region of the solution next to the electrode where concentrations are affected by the applied potential. The thickness of the diffusion layer is a function of diffusion coefficient and time, $(D t)^{1 / 2}$. As the diffusion layer thickness approaches the size of the electrode, edge effects become more dominant. The impact of electrode size and geometry on charge injection capacity prevents reporting of a single value for an electrode material. Careful control of safe charge injection will become more important as the electrode size is reduced. It will also vary slightly on every hand-made cochlear implant electrode with different effective electrode areas.

By reducing the potential window, charge associated with different Faradaic reactions can be greatly diminished. This can also affect the ratio of oxidation to reduction charge. For instance, scanning the potential only between 0.8 and $0.2 \mathrm{~V}$ resulted in a 2 times greater oxidation charge injection capacity than reduction (figure 3 ). The definition of safe potential window will therefore determine the degree of Faradaic charge allowed and subsequently the charge injection capacity and equivalency of reduction to oxidation charge of an electrode.

Solution composition impacts the charge injection mechanism and capacity, and subsequently the ratio of oxidation to reduction charge. Use of $\mathrm{PBS}$ rather than $0.1 \mathrm{M} \mathrm{NaCl}$ slightly increased the reduction charge but nearly doubled the oxidation charge, possibly due to phosphate adsorption, leading to a smaller ratio of reduction to oxidation charge injection capacity (figure 4). An artificial perilymph also had larger reduction and oxidation charges than $0.1 \mathrm{M} \mathrm{NaCl}$. Changes in electrolyte composition have also been shown to affect the charge injection capacity of iridium oxide electrodes [34]. Without degassing, the higher oxygen concentration enabled greater oxygen reduction current, increasing the total reduction charge and decreasing the oxidation charge, resulting in a doubling of the reduction to oxidation charge injection capacity from 1.4 to 2.8 (figure 5). The oxygen tension in the cochlear and other body fluids is quite low, as it is mostly bound to haemoglobin, but it varies with atmosphere and activity $[35,36]$. Therefore the most accurate measure of charge injection capacity and equivalency can only be obtained in a suitable biological solution (a degassed artificial perilymph for cochlear implants) or in vivo.

The structure of a platinum surface can also affect the charge injection mechanisms and charge injection capacity. On a mechanically polished electrode, the surface will be highly heterogeneous, rough and contain oxides and various impurities. Charge injection from these electrodes within the water window will be mostly attributed to capacitance, formation and removal of platinum oxide and adsorption and desorption of hydrogen. Acid polishing of platinum can remove many surface impurities and restructure the surface [37]. This can lead to an increase in effective surface area for hydrogen adsorption, increasing the charge injection capacity from the 
hydrogen adsorption process in acidic solutions (figure 6(b)). However the charge injection capacity in $0.5 \mathrm{M} \mathrm{H}_{2} \mathrm{SO}_{4}$ is of little relevance to biological solutions. When this acid polished electrode is placed into $0.1 \mathrm{M} \mathrm{NaCl}$, a significant change in voltammetric response is observed (figure 7). The large Faradaic peaks are most likely associated with adsorption of $\mathrm{Cl}^{-}$. Under different conditions, $\mathrm{Cl}^{-}$adsorption has been reported to occur synergistically with hydrogen or to block the hydrogen adsorption and oxide formation [20, 38, 39]. The charge injection mechanism from this electrode-solution interface is different from a mechanically polished electrode. The reduction charge increased from $54.9 \mu \mathrm{C}$ to $129.5 \mu \mathrm{C}(2.4$ times greater) and the oxidation charge increased from 19.8 $\mu \mathrm{C}$ to $76.7 \mu \mathrm{C}$ (3.9 times greater) from mechanically polished to acid polished. This resulted in a ratio of reduction to oxidation charge injection capacity of 2.7 and 1.7 from mechanical and acid polishing, respectively. While this may provide an avenue for optimising a platinum surface to increase the charge injection capacity and charge equivalency, the stability of nanostructured electrodes in vivo over many years of electrical stimulation hasn't been demonstrated [40].

\subsection{Effective electrode area and charge density}

Sufficient charge must be injected from an electrode into tissue to affect target cells. This is usually reported as a charge density. The nominal electrode area for the cochlear implant electrode used in this experiment was $0.3 \mathrm{~mm}^{2}$, although electrode areas vary due to manufacturing variations, position on the array (from base to apex) and the type of electrode used, affecting any charge density calculations. An accurate geometric area is difficult to measure on the curved electrodes and when thin layers of transparent silicone may be blocking the electrode surface.

Measurement of an effective electrode area can be achieved through electrochemical techniques. Voltammetry in $0.5 \mathrm{M}$ $\mathrm{H}_{2} \mathrm{SO}_{4}$ is routinely used to measure hydrogen adsorption. A baseline is drawn on the reductive sweep over the potential range of $\sim 100$ to $200 \mathrm{mV}$ to remove charge associated with capacitance and the remaining charge is measured from $\sim-200$ to $50 \mathrm{mV}$. If the charge density of hydrogen adsorption on platinum is known, the measured charge can be used to calculate an effective area. On a $2 \mathrm{~mm}$ nominal diameter $\left(0.031 \mathrm{~cm}^{2}\right)$, mechanically cleaned electrode, the hydrogen adsorption charge was initially $17.7 \mu \mathrm{C}$, increasing to 22.1 $\mu \mathrm{C}$ after 50 potential cycles. Assuming a hydrogen adsorption charge density of $210 \mu \mathrm{C} \mathrm{cm}^{-2}$ [41], this would give an effective electrode area of $0.084 \mathrm{~cm}^{2}$, increasing to $0.105 \mathrm{~cm}^{2}$ after cleaning. The roughness factor would therefore be 2.7 , increasing to 3.4 .

There are a number of assumptions made in using the hydrogen adsorption method of measuring effective electrode area [41]. The charge associated with hydrogen adsorption and hydrogen evolution overlap, making definition of the correct potential window extremely difficult [42]. Other Faradaic reactions may also be present, such as oxygen reduction, which can affect the accuracy of the charge measurement.
In subtracting the capacitance charge, a linear baseline is typically used; however the capacitance may not be a linear function of potential [43]. Measuring an accurate charge value can be further complicated by using modern digital potentiostats that use staircase voltammetry, and not analogue linear scan voltammetry [44]. The step height, step width, filtering method and measurement time can all affect the charge measurement. Once a charge value has been obtained, converting it to an effective electrode area is usually performed with a hydrogen adsorption charge density of $210 \mu \mathrm{C} \mathrm{cm}^{-2}$. This charge density assumes one hydrogen atom adsorbs onto every surface platinum atom of a (100) crystal plane. While the electrodes used in this study were not single crystals, the voltammetry of the mechanically cleaned platinum is similar to previous reports of platinum (111), where it was suggested that potential cycling into the oxide region led to growth of platinum (110) [45]. Although this shape of voltammetry was later attributed to adsorption of impurities from the atmosphere onto Pt (1 11 ), and not a pristine Pt (1 111$)$ surface [46]. The hydrogen adsorption density is different on each crystal plane, $241 \mu \mathrm{C} \mathrm{cm}^{-2}$ on the (111) plane and either 147 or 295 $\mu \mathrm{C} \mathrm{cm}^{-2}$ for the (110) plane depending on the definition of surface atom $[41,45]$. The surface density is harder to define on higher index planes and polycrystalline surfaces [46]. These adsorption densities are also determined from pristine single crystal planes where the edges of the electrodes have been masked [46]. The presence of steps, defects, electrode roughness and impurities can significantly impact on the accuracy of the hydrogen adsorption density.

Based on the assumptions of hydrogen adsorption on platinum, the measured effective electrode area is an equivalent (100) platinum electrode, and can include significant error in the charge measurement. Therefore the effective electrode area may not be accurate, but does allow comparison of platinum electrodes tested in an equivalent manner. More fundamentally, the effective electrode area is measured in a $0.5 \mathrm{M}$ $\mathrm{H}_{2} \mathrm{SO}_{4}$ solution, which has little resemblance to biological solutions. In biological solutions, the presence of other species such as chloride and organic species may block the electrode, resulting in a different effective electrode area. Charge is also injected via other reaction mechanisms such as capacitance which may not correlate well with the hydrogen adsorption effective area. Furthermore, the hydrogen adsorption mechanism is not available on most other materials proposed for bionic applications, such as doped conducting polymers and iridium oxide, and cannot be used to determine their effective electrode areas. This prevents comparison of the charge density of different materials.

Oxidation or reduction of a solution phase redox species such as $\mathrm{Ru}\left(\mathrm{NH}_{3}\right)_{6}^{3+}$ can be used to determine the effective electrode area used in charge transfer [22]. The method is robust, with $\mathrm{Ru}\left(\mathrm{NH}_{3}\right)_{6}^{3+}$ being detectable on most electrode surfaces and in different solution compositions [47-49]. This allows comparison of different electrode materials in biologically relevant solutions. The measured area is also more accurate than other techniques; not including blocked regions that would be included in a geometric area; and including 
Table 2. Charge density of platinum electrodes from different measurement techniques calculated with an effective electrode area determined by reduction of $\mathrm{Ru}\left(\mathrm{NH}_{3}\right)_{6}^{3+}$ at fast voltammetric scan rates.

\begin{tabular}{|c|c|c|c|c|c|c|}
\hline \multirow[b]{2}{*}{ Electrode diameter } & \multirow[b]{2}{*}{ Polish method } & \multirow[b]{2}{*}{ Solution } & \multirow[b]{2}{*}{$\begin{array}{l}\text { Scan rate } \\
\left(\mathrm{mV} \mathrm{s}^{-1}\right)\end{array}$} & \multirow[b]{2}{*}{$\begin{array}{l}\text { Potential } \\
\text { window (V) }\end{array}$} & \multicolumn{2}{|c|}{ Charge density $\left(\mathrm{mC} \mathrm{cm}^{-2}\right)^{\mathrm{a}}$} \\
\hline & & & & & $\begin{array}{l}\text { Reduction } \\
\text { sweep }\end{array}$ & $\begin{array}{l}\text { Oxidation } \\
\text { sweep }\end{array}$ \\
\hline $2 \mathrm{~mm}$ & Mechanical & $0.1 \mathrm{M} \mathrm{NaCl}$ & 100 & 0.8 to -0.8 & 1.61 & 1.14 \\
\hline $2 \mathrm{~mm}$ & Mechanical & $0.1 \mathrm{M} \mathrm{NaCl}$ & 20 & 0.8 to -0.8 & 3.99 & 1.79 \\
\hline $2 \mathrm{~mm}$ & Mechanical & $0.1 \mathrm{M} \mathrm{NaCl}$ & 500 & 0.8 to -0.8 & 1.47 & 1.14 \\
\hline $25 \mu \mathrm{m}$ & Mechanical & $0.1 \mathrm{M} \mathrm{NaCl}$ & 100 & 0.8 to -0.8 & 5.57 & 0.82 \\
\hline $2 \mathrm{~mm}$ & Mechanical & $0.1 \mathrm{M} \mathrm{NaCl}$ & 100 & 0.8 to 0.2 & 0.15 & 0.30 \\
\hline $2 \mathrm{~mm}$ & Mechanical & PBS & 100 & 0.8 to -0.8 & 2.67 & 1.91 \\
\hline $2 \mathrm{~mm}$ & Mechanical & Artificial perilymph & 100 & 0.8 to -0.8 & 1.67 & 1.49 \\
\hline $2 \mathrm{~mm}$ & Mechanical & PBS with Oxygen & 100 & 0.8 to -0.8 & 3.80 & 1.33 \\
\hline $2 \mathrm{~mm}$ & Acid & $0.1 \mathrm{M} \mathrm{NaCl}$ & 100 & 0.8 to -0.8 & 4.80 & 2.84 \\
\hline Cochlear implant & - & $0.1 \mathrm{M} \mathrm{NaCl}$ & 100 & 0.8 to -0.8 & 2.39 & 2.35 \\
\hline
\end{tabular}

a Effective electrode area: $2 \mathrm{~mm}$ diameter $=0.027 \mathrm{~cm}^{2}, 25 \mu \mathrm{m}$ diameter $=5.74 \times 10^{-6} \mathrm{~cm}^{2}$, Cochlear implant $=2.47 \times 10^{-3} \mathrm{~cm}^{2}$.

areas that enable charge transfer but may not allow hydrogen adsorption.

The effective area of the $2 \mathrm{~mm}$ nominal diameter electrode $\left(0.031 \mathrm{~cm}^{2}\right)$ measured by reduction of $\mathrm{Ru}\left(\mathrm{NH}_{3}\right)_{6}^{3+}$ at fast scan rates was $0.027 \mathrm{~cm}^{2}$. This is significantly smaller than the effective electrode area measured by hydrogen adsorption. The same technique provided an effective electrode area of $5.74 \times 10^{-6} \mathrm{~cm}^{2}$ at a $25 \mu \mathrm{m}$ diameter microelectrode $\left(4.91 \times 10^{-6} \mathrm{~cm}^{2}\right.$ nominal area) and $2.47 \times 10^{-3} \mathrm{~cm}^{2}$ on a cochlear implant electrode. Slow voltammetric scan rates could also provide a radial diffusion electroactive area of $3.5 \times 10^{-6} \mathrm{~cm}^{2}$ on the $25 \mu \mathrm{m}$ diameter microelectrode.

Various reports of the safe charge density of platinum and platinum-iridium range from $0.05-0.15$ [50], 0.3-0.35 [51] and 0.75 [52] $\mathrm{mC} \mathrm{cm}^{-2}$ depending on measurement technique. All of these values were determined from current pulsing rather than cyclic voltammetry. The lowest value was measured on acid cleaned electrodes using a geometric area in various buffered saline solutions [50]. The intermediate value utilised an effective electrode area determined from hydrogen adsorption and tested with acid cleaned electrodes in a simulated cerebrospinal fluid [51]. And the largest value was measured in the same manner but included a wider range of Faradaic reactions [52]. The charge density measured by cyclic voltammetry will be greater than that of a current pulse intended for neural stimulation due to the longer measurement time [24]. The charge density of a $1.4 \mathrm{~cm}^{2}$ geometric area platinum electrode measured from a reduction sweep of cyclic voltammetry in PBS at $20 \mathrm{mV} \mathrm{s}^{-1}$ was $0.55 \mathrm{mC} \mathrm{cm}^{-2}$ [53]. A value of $5.6 \mathrm{mC} \mathrm{cm}^{-2}$ was obtained in a model interstitial fluid at $50 \mathrm{mV} \mathrm{s}^{-1}$ of a $1105 \mu \mathrm{m}^{2}$ geometric area platinum-iridium electrode [54].

The charge density can be determined from different charge and area measurements. The effective electrode area determined by reduction of $\mathrm{Ru}\left(\mathrm{NH}_{3}\right)_{6}^{3+}$ at fast voltammetric scan rates is potentially the most relevant area. The charge density of platinum under different conditions is reported in table 2. Under this selection of conditions, the charge density of platinum ranged from 0.15 to $5.57 \mathrm{mC} \mathrm{cm}^{-2}$. Further variations in scan rate, potential window, electrode area, surface treatment and electrolyte could extend the range of charge density values achievable on a platinum electrode.

\section{Conclusions}

The electrochemical properties of platinum electrodes used for bionic applications have been investigated. The water window and safe potential window were affected to varying degrees by changes to electrolyte, size of the electrode, oxygen concentration and differences in electrode polishing method. The charge injection capacity had contributions from capacitance and Faradaic current. Changes to voltammetric scan rate (measurement time), electrode size, electrode polishing method, potential window, electrolyte and oxygen concentration affected the charge injection capacity and the ratio of oxidation to reduction charge. The electrode area could be determined from different measurement techniques. Hydrogen adsorption in acidic solutions can provide an effective electrode area which is inaccurate, but capable of comparing electrodes measured by the same technique. Reduction of a solution phase redox species could provide an effective electrode area determined by a linear or radial diffusion profile. The charge density of a platinum electrode is dependent on the charge injection capacity and electrode area measurement technique. The charge density of platinum measured by cyclic voltammetry ranged from 0.15 to 5.57 $\mathrm{mC} \mathrm{cm}{ }^{-2}$.

\section{Acknowledgments}

The authors acknowledge the financial support of the HEARing CRC, established and supported under the Australian Government's Cooperative Research Centres Program. GGW is also grateful to the ARC for support under the Australian Laureate Fellowship scheme (FL110100196). The authors thank the Materials Node of Australian National Fabrication Facility (ANFF) and acknowledge use of the facilities. 
Alexander R Harris (으 https://orcid.org/0000-0002-5826-8777

\section{References}

[1] McIntyre C C, Chaturvedi A, Shamir R R and Lempka S F 2015 Engineering the next generation of clinical deep brain stimulation technology Brain Stimul. 8 21-6

[2] deSouza R-M, Moro E, Lang A E and Schapira A H V 2013 Timing of deep brain stimulation in Parkinson disease: a need for reappraisal? Ann. Neurol. 73 565-75

[3] Kennedy S H et al 2011 Deep brain stimulation for treatment-resistant depression: follow-up after 3 to 6 years Am. J. Psychiatry (https://doi.org/10.1176/appi. ajp.2010.10081187)

[4] da Cruz L et al 2013 The Argus II epiretinal prosthesis system allows letter and word reading and long-term function in patients with profound vision loss British J. Ophthalmol.

[5] Clark G 2009 The multi-channel cochlear implant: past, present and future perspectives Cochlear Implants Int. 10 2-13

[6] Clark G 2003 Cochlear Implants: Fundamentals and Applications (Berlin: Springer)

[7] Biran R, Martin D C and Tresco P A 2005 Neuronal cell loss accompanies the brain tissue response to chronically implanted silicon microelectrode arrays Exp. Neurol. $195115-26$

[8] Ishai R, Herrmann B S, Nadol J B Jr and Quesnel A M 2017 The pattern and degree of capsular fibrous sheaths surrounding cochlear electrode arrays Hear. Res. 348 44-53

[9] Abidian M R and Martin D C 2009 Multifunctional nanobiomaterials for neural interfaces $A d v$. Funct. Mater. 19 573-85

[10] Green R A, Baek S, Poole-Warren L A and Martens P J 2010 Conducting polymer-hydrogels for medical electrode applications Sci. Technol. Adv. Mater. 11014107

[11] Cui X, Hetke J F, Wiler J A, Anderson D J and Martin D C 2001 Electrochemical deposition and characterization of conducting polymer polypyrrole/PSS on multichannel neural probes Sensors Actuators A 93 8-18

[12] Harris A R and Wallace G G 2017 Organic electrodes and communication with excitable cells Adv. Funct. Mater. aceepted.

[13] Green R A et al 2013 Performance of conducting polymer electrodes for stimulating neuroprosthetics J. Neural Eng. 10016009

[14] Cui X T and Zhou D D 2007 Poly

(3,4-Ethylenedioxythiophene) for chronic neural stimulation IEEE Trans. Neural Syst. Rehabil. Eng. 15 502-8

[15] Merrill D R, Bikson M and Jefferys J G R 2005 Electrical stimulation of excitable tissue: design of efficacious and safe protocols J. Neurosci. Methods 141 171-98

[16] Jiang J and Kucernak A 2002 Nanostructured platinum as an electrocatalyst for the electrooxidation of formic acid J. Electroanal. Chem. 520 64-70

[17] Gangeri $\mathrm{M}$ et al 2005 Electrocatalytic performances of nanostructured platinum-carbon materials Catal. Today $10250-7$

[18] Salt A N, Kellner C and Hale S 2003 Contamination of perilymph sampled from the basal cochlear turn with cerebrospinal fluid Hear. Res. 182 24-33

[19] Ye S, Kita H and Aramata A 1992 Hydrogen and anion adsorption at platinum single crystal electrodes in phosphate solutions over a wide range of $\mathrm{pH}$ J. Electroanal. Chem. 333 299-312
[20] Bagotzky V S, Vassilyev Y B, Weber J and Pirtskhalava J N 1970 Adsorption of anions on smooth platinum electrodes J. Electroanal. Chem. Interfacial Electrochem. 27 31-46

[21] Brummer S B and Turner M J 1977 Electrical stimulation with Pt electrodes: a method for determination of 'Real' electrode areas IEEE Trans. Biomed. Eng. BME-24 436-9

[22] Harris A R, Molino P J, Kapsa R M I, Clark G M, Paolini A G and Wallace G G 2015 Optical and electrochemical methods for determining the effective area and charge density of conducting polymer modified electrodes for neural stimulation Anal. Chem. 87 738-46

[23] Kumsa D W, Bhadra N, Hudak E M, Kelley S C, Untereker D F and Mortimer J T 2016 Electron transfer processes occurring on platinum neural stimulating electrodes: a tutorial on the i ( $\mathrm{V}$ e) profile J. Neural Eng. 13052001

[24] Beebe X and Rose T L 1988 Charge injection limits of activated iridium oxide electrodes with $0.2 \mathrm{~ms}$ pulses in bicarbonate buffered saline (neurological stimulation application) IEEE Trans. Biomed. Eng. 35 494-5

[25] Osterloh F E 2008 Inorganic materials as catalysts for photochemical splitting of water Chem. Mater. 20 35-54

[26] Michaud P-A, Panizza M, Ouattara L, Diaco T, Foti G and Comninellis C 2003 Electrochemical oxidation of water on synthetic boron-doped diamond thin film anodes J. Appl. Electrochem. 33 151-4

[27] Hara A, Salt A N and Thalmann R 1989 Perilymph composition in scala tympani of the cochlea: influence of cerebrospinal fluid Hear. Res. 42 265-71

[28] Wangemann P 2006 Supporting sensory transduction: cochlear fluid homeostasis and the endocochlear potential J. Physiol. $57611-21$

[29] Hudak E M, Mortimer J T and Martin H B 2010 Platinum for neural stimulation: voltammetry considerations J. Neural Eng. 7026005

[30] Ledo A, Lourenço C F, Laranjinha J, Brett C M A, Gerhardt G A and Barbosa R M 2017 Ceramic-based multisite platinum microelectrode arrays: morphological characteristics and electrochemical performance for extracellular oxygen measurements in brain tissue Anal. Chem. 89 1674-83

[31] Kumsa D W, Montague F W, Hudak E M and Mortimer J T 2016 Electron transfer processes occurring on platinum neural stimulating electrodes: pulsing experiments for cathodic-first/charge-balanced/biphasic pulses for $0.566 \leqslant \mathrm{k} \leqslant 2.3$ in oxygenated and deoxygenated sulfuric acid J. Neural Eng. 13056001

[32] Kumsa D W, Bhadra N, Hudak E M and Mortimer J T 2017 Electron transfer processes occurring on platinum neural stimulating electrodes: pulsing experiments for cathodicfirst, charge-balanced, biphasic pulses for $0.566<\mathrm{k}<2.3$ in rat subcutaneous tissues J. Neural Eng. 14056003

[33] Cogan S F, Ehrlich J and Plante T D ed 2014 The effect of electrode geometry on electrochemical properties measured in saline 2014 36th Annual Int. Conf. of the IEEE Engineering in Medicine and Biology Society (26-30 August 2014)

[34] Cogan S F, Troyk P R, Ehrlich J, Gasbarro C M and Plante T D 2007 The influence of electrolyte composition on the in vitro charge-injection limits of activated iridium oxide (AIROF) stimulation electrodes J. Neural Eng. 479

[35] Misrahy G A, Shinabarger E W and Arnold J E 1958 Changes in cochlear endolymphatic oxygen availability, action potential, and microphonics during and following asphyxia, hypoxia, and exposure to loud sounds J. Acoust. Soc. Am. $30701-4$

[36] Tsunoo M and Perlman H B 1965 Cochlear oxygen tension: relation to blood flow and function Acta Oto Laryngol. 59 437-50 
[37] Aberdam D, Durand R, Faure R and El-Omar F 1986 Structural changes of a Pt (1 111 ) electrode induced by electrosorption of oxygen in acidic solutions: a coupled voltammetry, LEED and AES study Surf. Sci. $171303-30$

[38] Li N and Lipkowski J 2000 Chronocoulometric studies of chloride adsorption at the $\operatorname{Pt}(111)$ electrode surface $J$. Electroanal. Chem. 491 95-102

[39] Garcia-Araez N, Climent V, Herrero E, Feliu J and Lipkowski J 2005 Thermodynamic studies of chloride adsorption at the $\mathrm{Pt}(111)$ electrode surface from $0.1 \mathrm{M}$ $\mathrm{HClO}_{4}$ solution J. Electroanal. Chem. 576 33-41

[40] Desai S A, Rolston J D, Guo L and Potter S M 2010 Improving impedance of implantable microwire multielectrode arrays by ultrasonic electroplating of durable platinum black Front. Neuroeng. 3

[41] Biegler T, Rand D A J and Woods R 1971 Limiting oxygen coverage on platinized platinum; relevance to determination of real platinum area by hydrogen adsorption J. Electroanal. Chem. Interfacial Electrochem. 29 269-77

[42] Woods R 1974 Hydrogen adsorption on platinum, iridium and rhodium electrodes at reduced temperatures and the determination of real surface area J. Electroanal. Chem. Interfacial Electrochem. 49 217-26

[43] Climent V and Feliu J M 2011 Thirty years of platinum single crystal electrochemistry J. Solid State Electrochem. 151297

[44] Hai B, Tolmachev Y V, Loparo K A, Zanelli C and Scherson D 2011 Cyclic versus staircase voltammetry in electrocatalysis: theoretical aspects J. Electrochem. Soc. 158 F $15-9$

[45] Yamamoto K, Kolb D M, Kötz R and Lehmpfuhl G 1979 Hydrogen adsorption and oxide formation on platinum single crystal electrodes J. Electroanal. Chem. Interfacial Electrochem. 96 233-9

[46] Ross P N Jr 1981 Hydrogen chemisorption on Pt single crystal surfaces in acidic solutions Surf. Sci. 102 463-85

[47] Harris A R, Molino P J, Kapsa R M I, Clark G M, Paolini A G and Wallace G G 2016 Effective area and charge density of dextran sulphate doped PEDOT modified electrodes Synth. Met. 220 394-401

[48] Harris A R, Molino P J, Paolini A G and Wallace G G 2016 Effective area and charge density of chondroitin sulphate doped PEDOT modified electrodes Electrochim. Acta 197 99-106

[49] Harris A R, Paolini A G and Wallace G G 2017 Effective area and charge density of iridium oxide neural electrodes Electrochim. Acta 230 285-92

[50] Rose T L and Robblee L S 1990 Electrical stimulation with Pt electrodes. VIII. Electrochemically safe charge injection limits with $0.2 \mathrm{~ms}$ pulses (neuronal application) IEEE Trans. Biomed. Eng. 37 1118-20

[51] Brummer S B and Turner M J 1977 Electrical stimulation with Pt electrodes: II-estimation of maximum surface redox (theoretical non-gassing) limits IEEE Trans. Biomed. Eng. BME-24 440-3

[52] Brummer S B and Turner M J 1977 Electrochemical considerations for safe electrical stimulation of the nervous system with platinum electrodes IEEE Trans. Biomed. Eng. BME-24 59-63

[53] Cogan S F 2008 Neural stimulation and recording electrodes Annu. Rev. Biomed. Eng. 10 275-309

[54] Cogan S F, Troyk P R, Ehrlich J and Plante T D 2005 In vitro comparison of the charge-injection limits of activated iridium oxide (AIROF) and platinum-iridium microelectrodes IEEE Trans. Biomed. Eng. 52 1612-4 